\title{
Application of Task-based Approach in English Teaching
}

\author{
Xiaoyan LI \\ Wuhan Institute of Technology, 430205, Wuhan
}

\begin{abstract}
Task-based approach is a student-centered teaching method aiming at promoting students' language acquisition and communicative competence. Compared to the traditional teaching method, task-based approach can motivate students to learn English and enable them to gain sense of success. Therefore, it can be widely applied in English teaching.
\end{abstract}

Keywords: task-based approach; application; English teaching

\section{Introduction}

Task-based approach (TBA for short) has developed gradually since 1980s. It's a language teaching method which has been widely recognized and accepted by a large quantity of linguists and practitioners of foreign language teaching. Meanwhile, it's also a teaching approach which has been highly recommended by Middle School Curriculum Standards established by Chinese Ministry of Education. TBA, putting emphasis on learning by doing, is the development of communicative teaching approach and has attracted widespread attention in the world of language education. The theory of doing things with the language is gradually introduced to the Basic English teaching in China. According to this theory, mastering language is not the result of the training of language skills and the acquisition of language knowledge, but the result of the using of language through taking part in various kinds of activities. Based on the specific teaching objectives, teachers design a variety of teaching activities, through which students can work together to accomplish language learning tasks and eventually achieve the goal of learning language and mastering language as well. Therefore, by attaching importance to students' cooperative learning, TBA fully reflects the student-centered teaching philosophy.

\section{Task-based approach}

With student-centered being the core, TBA is theoretically based on the popular constructivism. According to Fosnot (2005), constructivism is a theory about knowledge and learning. The theory believes that human cognition develops with their experience, that knowledge is the restructuring and rebuilding of experience and is a process of constant psychological constructing, experiencing, discovering and creating. TBA provides students with this valuable process. By taking part in different kinds of activities, students restructure and rebuild their knowledge, making the existing knowledge they have already had and the new one they have just taken in interact and blend with each other. Once students gain sense of success in construct the new knowledge, they will become more active in taking part in activities, forming a benign circulation in language learning.

\subsection{Definitions of task}

Based on their different researches, scholars give definitions to task from different perspectives. In the eyes of Prabhu (1987), task is an activity which needs people to draw a conclusion from the given information after consideration. It is the teacher who controls and regulates this process. As far as Nunan (1989) is concerned, communicative task is a classroom activity that requires students to use the target language to understand, practice, use or communicate, in which process students concentrate on the 
meaning instead of the form of language. According to Long \& Crookes (1991), task is either voluntary or paid work people do for themselves or for others. Willis (1996) believes task is a communicative activity with a certain purpose or a process that students take communicative activity in order to achieve a certain purpose. According to Skehan (1998), task is an activity that has a meaningful connection with the real world. Ellis (1999) thinks task is a meaning-centered activity to use a language.

Judging from the above-mentioned definitions, it can be seen that task-based learning is not limited to language practice. Instead, it's a process of learning by doing. That teachers teach a language in class is not to let students memorize isolated words, sentences or boring grammar rules, but to design an activity which can effectively combine vocabulary, grammar and function. This process enables students to interact with each other and acquire language at the same time.

\subsection{Categories of task}

Just as different scholars give different definitions to task, people classify task in a different way.

Based on the impacts produced in the process of finishing a task, task can be divided into the following five categories.

The first category is jigsaw task, which requires students to bring pieces of scattered information together to make a whole. For instance, students can be divided into several groups. Each group is supposed to write a part of a story, then all the groups work together to make a complete story by combining all the parts. The second is information gap task, which means different groups of students have different information which is complementary to each other. Those groups with complementary information have to cooperate well to get the information of the other side so as to accomplish a communicative activity. The third is problem solving task which means giving students one problem along with a series of information and asking them to find a solution, generally speaking, only one solution, to the problem. The fourth is decision making task which means giving students a problem with several possible results. Students have to discuss and negotiate with each other so that they can come to an agreement on one result. The fifth is opinion exchange task which means students discuss with each other and exchange their ideas, but they needn't reach an agreement.

Each category of task has its unique features. Teachers can adopt one or more categories in designing class activities.

\subsection{Models of task-based approach}

According to Skehan (1998), there can be three different models of task-based approach, namely, structure-based, communication-driven, and intermediate position. Structure-based model puts emphasis on the using of a certain language form, under which circumstance students are usually required to use a specific language structure in the process of finishing a task. By urging students to practice the same language structure, this teaching model can enable them to master the language structure effectively in the given time. While structure-based teaching model stresses the language form, communication-driven teaching model places focus on the naturalness and authenticity of the task. Willis (1996) points out that the task which suits the natural and real situation enables students to make great progress in language acquisition, and the implementation of task is mainly for communicative purpose rather than linguistic norms. Task shouldn't be designed just for some particular language structure. Instead, the designing of task should be driven by the need of the real world so as to accelerate the process of language acquisition and promote the development of interlanguage. Different from structure-based and communication-driven models, intermediate-position teaching model puts emphasis on task's naturalness and authenticity as well as the practice of some certain language structure to advance the 
development of interlanguage. In order to strike the balance between the two, task has to be designed and carried out after careful consideration and proper choice.

The above-mentioned three models of TBA have their own focus. Numerous practices and researches at abroad have proved that the intermediate-position model is the most effective. Therefore, it can be applied to the teaching of College English in China, which acts as a complement to the traditional teaching model.

\section{Application of task-based approach in College English teaching}

TBA takes three steps to design a class activity, that is, pre-task, task-cycle, and post-task. Pre-task, aiming at introducing the topic and stimulating students' interests, is the task assigned by teachers to students which requires them to work individually or in groups to do preparations. Looking for some information or doing a research is often involved. By choosing and designing the proper tasks, teachers play the role of selectors in this process. Task-cycle is the process in which students learn by doing, for instance, by participating, practicing and cooperating, to achieve the goal of developing their comprehensive skills. Post-task involves students' showing their results and the evaluation of both students' and the teacher's. The following part takes Unit 4 in Now College English Integrated Course Book 3 to see how TBA can be applied in College English teaching. The topic for this unit is imagination and creativity. It consists of two texts, one is Was Einstein a Space Alien, and the other is Anecdotes about Einstein.

\subsection{Pre-task}

The teacher assigns a specific task to students before learning this unit, that is, students are supposed to search for information about scientists and their great achievements.
The following questions can be asked to lead in this unit: What is imagination? What is creativity? Do you think you are imaginative and creative? Do others think you are imaginative and creative? Can you name some imaginative and creative scientist and their great achievements? What characteristic do they have in common?

The first two questions need students to give a simple definition to the two words which can promote students' thinking ability. Then the teacher may show students some pictures, among which the most famous one is to find as many faces as possible. Students can work in pairs or even in group. This can help students decide whether they are imaginative or not. As to famous scientists and their great achievements, since students have already looked for the relevant material, everyone has something to say. They needn't to be worried or anxious. Students can work in groups in order to avoid giving same answers. After each group presents their different answers, the whole class can work together to find the common characteristics those famous scientists have, for example, knowledgeable, imaginative, curious, persistent, etc. This is a decision-making task which needs students to come to an agreement on characteristics the famous scientists have. This process develops students' ability of analyzing and induction. More importantly, the common characteristics can be also applicable for students to achieve success in their study at campus.

\subsection{Task-cycle}

In lead-in part, some groups may mention Einstein and his great achievements. Then teacher may assign the first task to students in the process of task-cycle: are the achievements you've found the same as what are mentioned in the text A? In order to answer this question, students have to scan the text to look for the information they need. It's highly probable that students have found different achievements from those mentioned in the text, which effectively broaden students' horizon and contribute to language acquisition as well. 
Then, the teacher draws students' attention to the title: was Einstein a space alien? The answer to this question may be yes or no, so the class can be divided into two groups, with one group looking for the evidence for the answer "yes" and the other group looking for the evidence for the answer "no". This process requires students to read the text carefully and distinguish the evidence from other irrelevant detailed sentences. This can be called a decision-making task. To achieve this, students have to cooperate well to reach an agreement, which contributes to the development of their team-work spirit as well as their ability of analyzing and induction.

After understanding the main idea of the text, another task can be designed to pick out those important and frequently used words and phrases. One student makes a sentence with one given word or phrase, and the second student adds a second sentence by using a different word or phrase to make the story logical, and the third student adds a third sentence, etc. Students keep on making the story until all the words and phrases have been used and all the students take part in this activity. It can be seen obviously that this is a jigsaw task with all the students contributing to make a whole story. Intermediate-position teaching model is adopted in this process since students not only learn the given language structures but also practice their communicative ability.

Next, another task is assigned to students: ask students to work in groups to discuss the role of creativity in children's education. Then each group choose a speaker to report their discussion to the whole class. Students can refer to the role of imagination in the advancement of science mentioned in the text. This is an opinion exchange task which requires students to take part in the discussion and exchange their ideas.

\subsection{Post-task}

Post-task involves both the students and the teacher to evaluate their performance. The performance may be evaluated by the student himself, or by the group, or by the teacher. For example, when a student is speaking, the rest of the class listens attentively and then some students are chosen to make comments on the speaker's remarks. This activity provides students with opportunities to practice their ability of listening as well as speaking. Positive evaluation can let students reap the benefits of success, which can motivate them to be more active to take part in all kinds of class activities. Meanwhile, the teacher also gives feedbacks to all the participants.

\section{Conclusion}

Task-based approach provides students with numerous kinds of activities, and brings them a brand new feeling. It not only stimulates students' interest, create an active atmosphere, but also cultivates students' ability to use English in a well-rounded way. Giving students a problem to solve or a task to finish can arouse students' curiosity. Students can gain sense of success after solving a problem or finishing a task. By contrast, a traditional teaching approach is not likely to achieve this effect. Therefore, task-basked approach can be widely applied to English teaching, but some factors including the designing of tasks and the degree of difficulty have to be taken into careful consideration.

\section{References}

[1] Catherine Twomey Fosnot. Constructivism: Theory, Perspectives, and Practice[M]. New York: Teachers College Press, 2005.

[2] FANG Wen-li. Task-based Approach in Foreign Language Teaching [J]. Foreign Language and Their Teaching, 2003(9): 17-20.

[3] Long, M. \& G. Crookes. 1991. Three Approaches to Task-based Syllabus Design[J]. TESOL Quarterly 26: 27-55. 
[4] Nunan, D. Designing Tasks for the Communicative Classroom[M]. Cambridge: Cambridge University Press, 1989.

[5] Peter Skehan. A Cognitive Approach to Language Learning[M]. Oxford: Oxford University Press, 1998.

[6] Prabhu, N.S. Second Language Pedagogy [M]. Oxford: Oxford University Press, 1987.
[7] Rod Ellis. The Study of Second Language Acquisition[M]. Shanghai: Shanghai Foreign Language Education Press, 1999.

[8] Willis, J. A Framework for Task-based Learning[M]. London: Addison Wesley Longman Limited, 1996. 